\title{
NILAI-NILAI BUDAYA DALAM LEGENDA SITI PAYUNG
}

\author{
Dila Handayani ${ }^{1}$, Dedy Rahmad Sitinjak ${ }^{2}$, Rini Salsa Bella Hardi ${ }^{3}$ \\ ${ }^{1}$ Universitas Tjut Nyak Dhien : february_8905@yahoo.com \\ ${ }^{2}$ Universitas Sumatera Utara : dedyrahmadsitinjak@gmail.com \\ ${ }^{3}$ Universitas Sumatera Utara : Rinisbh@gmail.com
}

\begin{tabular}{cl}
\multicolumn{2}{c}{ Artikel Info } \\
\hline Received & $: 15$ Sep 2021 \\
Accepted & $: 30$ Okt 2021 \\
Published & $: 29$ Nov 2021
\end{tabular}

\section{A. PENDAHULUAN}

Masyarakat Melayu merupakan salah satu masyarakat yang memiliki kekayaan kebudayaan yang bermacam ragam. Ralp linton (dalam Sibarani, 2004:6) menyatakan bahwa bentuk kebudayaan yang ada pada masyarakat terbagi menjadi dua jenis yaitu covert culture (kebudayaan inti yang tersimpan dalam diri manusia) seperti nilai budaya, ide dan norma, serta overt culture (kebudayaan luar) seperti tindakan berpola dan wujud benda hasil karya manusia. Pada dasarnya kebudayaan merupakan harta warisan yang berhaga yang dapat diwariskan kepada generasi muda.

Warisan kebudayaan dapat dibagi menjadi dua jenis yang pertama budaya berupa benda (tangible cultural heritage) contoh budaya berupa benda ini seperti situs, bangunan dan monumen bersejarah buatan manusia kemudian budaya tak benda 
(intangible cultural heritage) contohnya seperti tradisi lisan atau folklor.

Secara etimologi Folklor berasal dari bahasa inggris Folklore ini terdiri dari dua kata yaitu folk dan lore namun jika diartikan secara keseluruhan, oleh Brunvand dalam Danandjaja (1984:2) Folklor memiliki arti sebahagian kebudayaan suatu kolektif, yang tersebar dan diwariskan turun temurun diantara macam kolektif apa saja, secara tradisonal dalam versi yang berbeda, baik dalam bentuk lisan maupun contoh yang disertai gerak isyarat atau alat bantu pengingat, salah satu contoh folklor adalah cerita rakyat.

Djamaris (dalam Setiawan 2013: 8) menyatakan Cerita rakyat adalah suatu golongan cerita yang hidup dan berkembang secara turun-temurun dari suatu generasi ke generasi selanjutnya yang dikatakan sebagai cerita rakyat karena cerita itu hidup dan berkembang di kalangan masyarakat dan semua lapisan masyarakat mengenal ceritanya.

Cerita rakyat pada umumnya mengisahkan tentang suatu kejadian pada masa lampau biasanya cerita rakyat diawali dengan kalimat "pada zaman dahulu" namun tidak menyebutkan wakktu atau tahun kejadian dari cerita tersebut.

Ada sangat banyak sekali katagori daripada cerita rakyat. Namun pada dasarnya, cerita rakyat dapat dibagi menjadi tiga golongan besar diantaranya: Mite (myth), legenda (legend), dan dongeng (folktale) (Bascom, 1965, terjemahan, Danandjaja, J, 1984: 50).

Dari ketiga jenis cerita rakyat tersebut diatas salah satu yang menarik untuk dikaji atau dianalisis adalah legenda, Menurut Hasanuddin WS (2009:555), legenda diambil dari istilah Inggris, legend yaitu cerita rakyat yang berisikan tentang tokoh, peristiwa, atau tempat tertentu yang mencampurkan fakta historis dengan mitos.

Menurut Emeis (dalam Djamaris, 1990:98), legenda merupakan bagian dari cerita rakyat yang dianggap pernah terjadi, yang mana ceritanya masih kuno dan setengahnya berdasarkan sejarah dan setengahnya lagi angan-angan. Salah satu bentuk cerita rakyat berjenis legenda yaitu Legenda Siti Payung.

Legenda Siti Payung adalah legenda yang hidup di tengah masyarakat Batu Bara, khususnya di desa Dahari Silebar. Legenda Siti Payung bermula dari cerita seorang anak remaja yang bernama Kamaruddin. Kamaruddin adalah anak orang miskin, pekerjaan ayahnya adalah pencari kayu bakar untuk di jual ke kota, suatu saat Kamaruddin ingin pergi merantau ke kota namun di larang oleh ayah dan ibunya, kemudian Kamaruddin meminta izin kepada nenek nya namun penolakan yang sama juga terjadi sehingga Kamaruddin memutuskan tinggal bersama neneknya dan membantu neneknya merajut benang untuk dijadikan kerajinan tangan menjadi bunga.

Semenjak Kamaruddin membantu neneknya merajut benang menjadi bunga, hasilnya kerajinan tangan yang dirajut oleh Kamaruddin sangat bagus sehingga hampir setiap neneknya pergi kota menjual bunga mendapatkan untung yang bayak karena semua bunga habis terjual hingga suatu saat putri raja yang bernama Siti Payung membeli bunga yang dijual oleh neneknya Kamaruddin.

Siti Payung merupakan putri raja yang baik dan cantik bayak putra dari kerajaan yang lain ingin meminangnya namun ternyata siti payung memilih Kamaruddin menjadi suaminya hingga akhirnya terjadilah perang antara 7 kerajaan melawan kerajaan yang dipimpin oleh ayahnya Siti Payung.

Singkat cerita 7 kerajaan dikalahkan oleh seorang pendekar berpakaiaan serba hijau, berkuda yang kecepatannya seperti kilat, pendekar tersebut selalu merahasiakan identitasnya hingga akhirnya identitas pendekar tersebut terbongkat dan ternyata kesatria tersebut adalah Kamaruddin.

Dari sinopsis cerita Legenda Siti Payung di atas dapat diambil kesimpulan 
sementara bahwa Legenda Siti Payung mengandung nilai-nilai budaya yang dapat diambil dan dijadikan sebagai edukasi kepada generasi muda khususnya generasi muda masyarakat Melayu di Kabupaten Batu Bara. Untuk mengetahui nilai budaya yang terkandung dalam Legenda Siti Payung maka perlu dilakukan penelitian atau analisis yang lebih mendalam.

Dalam pendekatan Antropologi sastra nilai-nilai budaya merupakan salah satu bentuk analisis yang digunakan dalam menganalisis cerita rakyat berupa legenda. Menurut Djamaris (1996:3) nilai budaya dibagi atas beberapa sub bagian, yaitu: 1 . Nilai budaya dalam hubungan manusia dengan Tuhan, 2. Nilai budaya dalam hubungan manusia dengan alam, 3. Nilai budaya dalam hubungan manusia dengan masyarakat, 4. Nilai budaya dalam hubungan manusia dengan manusia lain, 5. Nilai budaya dalam hubungan manusia dengan diri sendiri.

Kelima bagian jenis nilai budaya yang dikemukakan oleh Djamaris tersebut dapat dijadikan sebagai teori untuk mengetahui bagai mana bentuk-bentuk nilai dari kelima nilai yang dikemukaan oleh Djamaris yang terdapat dalam legenda Siti Payung.

Kajian terdahulu tentang nilai-nilai budaya ini dapat dilihat pada kajian ilmiah

Febriant (2018) Pada artikel jurnalnya yang berjudul Nilai-Nilai Budaya Dalam Cerita Rakyat Kalimantan Barat Burung Arue Dan Burung Talokot dalam kajiannya Febrianti menyimpulkan analisis nilai-nilai budaya dan struktur pembangun cerita, cerita rakyat Burung Arue dan Burung Talokot mengandung nilai-nilai budaya luhur yang masih diterapkan oleh masyarakat pemiliknya hingga sekarang. Nilai-nilai tersebut antara lain rumah adat (nilai kebersamaan, kekeluargaan, dan solidaritas tenggang rasa), burung sebagai simbol budaya (nilai kesetiaan dan nilai kearifan), sumber daya alam, bersyukur kepada Tuhan (nilai religi), menepati janji dan amanah, nilai kasih sayang, nilai kesabaran, dan menjaga persaudaraan.

Kemudian Merdiyatna (2019) Pada artikel jurnalnya yang berjudul Nilai-Nilai Budaya Dalam Cerita Rakyat Panjalu dalam kajiannya Merdiyatna menyimpulkan 2 kesimpulan yaitu Kesatu: Bahwa struktur cerita rakyat yang telah dihimpun dan dianalisis mengandung unsur fakta cerita atau struktur faktual. Hal itu dibuktikan dari kedua cerita memunculkan tokoh, latar, dan alur. Kedua: Peneliti menemukan nilainilai budaya yang terkandung dalam cerita. Nilai-nilai budaya tersebut merupakan bagian dari nilai luhur budaya bangsa. Nilainilai budaya itu pun berkaitan erat dengan hubungan manusia dengan Penciptanya (religius), hubungan manusia dengan sesama makhluk (sosial), hubungan manusia dengan karyanya, dan hubungan manusia dengan alam.

Dari kedua penelitian terdahulu di atas memberi pengetahuan dan wawasan tentang nilai-nilai kebudayaan. Namun dua penelitian terdahulu tersebut berbeda dengan penelitian ini karena objek kajiannya berbeda. Untuk lebih memahami nilai budaya yang dikemukaan oleh Djamaris dibawah ini akan di deskripsikan kelima nilai budaya tersebut.

\section{Nilai budaya dalam hubungan manusia dengan Tuhan}

Manusia sebagai ciptaan Tuhan tentu memiliki keterikatan atau hubungan secara garis vertikal yang menjadi landasan setiap orang untuk memeluk atau meyakini keyakinan agama tertentu. Adanya harapan yang diminta lewat doa kepada sang pencipta merupakan sebuah nilai spiritual yang dapat menghubungkan manusia dengan penciptanya, selain berdoa berbagai cara dilakukan manusia untuk menjalin hubungan dengan Tuhannya seperti melaksanakan perintah dan menjauhi larangannya ini semua agar semua manusia merasakan ketenangan, kenyamanan serta seluruh hal yang diharapkan dapat dikabulkan oleh sang Maha Pencipta. 
Sebagai manusia yang beragama tentu manusia sangat membutuhkan Tuhan olehkarenanya melakukan ibadah sesuai dengan ajaran agamanya dan berusaha menghindari segala larangan yang ada dalam agama tersebut membuktikan bahwa manusia merupakan hambanya Tuhan.

Setiap kehidupan tentu memiliki dinamika setiap dinamika kehidupan menyadarkan manusia bahwa sesungguhnya manusia hanyalah mahluk yang lemah sehingga perlu adanya tempat mengadu, tempat berlindung secara spiritual agar dapat menentramkan hati manusia.

Manusia adalah makhluk yang religius dalam arti bahwa manusia menyembah Tuhan, pelaksanaan ritual ibadah atau upacara tertentu bertujuan untuk minta ampun, pertologan, kemudahan atau rezeki yang berlimpah merupakan nilai yang menunjukkan bahwa manusia memiliki dengan Tuhan maka dapat disimpulkan bahwa nilai Budaya dalam Hubungan Manusia dengan tuhan antara lain nilai suka berdoa, berserah diri, nilai ketakwaan, dan menyerah kepada takdir.

2. Nilai budaya dalam hubungan manusia dengan alam

Alam menyediakan segala sesuatu yang dibutuhkan manusia namun manusia terkadang rakus dalam mengelola sumber alam yang ada sehingga mengakibatkan eksploitasi yang berlebihan terhadap alam, kondisi tersebut jika dibiarkan maka alam akan marah terhadap manusia, bentuk marahnya alam itu seperti bencana alam yang dapat menelai korban jiwa. belakangan ini sering kita dengarkan tentang kampanye menjaga lingkungan atau alam agar bencana yang lebih besar terhindar dari kita semua, pemanasan global yang menjadi issue besar tentang lingkungan mendorong manusia untuk lebih menjaga alam sehingga alam akan bersabat dengan manusia dengan kata lain menghindari bencana alam dengan menjaga alam itu sendiri.

Tindakan berikut di atas mengandung nilai hunbungan manusia dengan alam karena manusia menyadari bahwa alam sebagai sumberdaya harus dikelola dengan baik dan efesien dengan mempertimbangkan aspek pencemaran lingkungan sehingga tindakan menjaga alam tetap terjaga.

Nilai yang menonjol dalam hubungan manusia dengan alam adalah nilai peduli dengan lingkungan sekitar dan pemanfaatan alam dengan baik tanpa perlu melakukan eksploitasi terhadap alam.

\section{Nilai budaya dalam hubungan manusia dengan masyarakat}

Setiap manusia membutuhkan organisasi sebagai wadah untuk mencapai tujuan yang lebih besar, organisasi menjadi salahsatu yang sangat dibutuhkan manusia dalam melaksanakan aktivitas bermasyarakat karena dengan berorganisasi maka seorang manusia akan berusaha mematuhi atau mentaati nilai yang dijunjung pada organisasi atau kelompok masyarakat tersebut.

Nilai budaya dalam hubungan manusia dengan masyarakat adalah nilainilai yang berhubungan dengan kepentinggan para anggota masyarakat, bukan nilai yang mengutamakan kepentingan diri sendiri diatas kepentingan masyarakat yang lainya.

Individu atau perseorangan berusaha mematuhi nilai-nilai yang ada dalam masyarakat karena dia berusaha untuk menjunjung tinggi nilai kebersamaan yang ada dilingkunan masyarakatnya, dengan demikian maka kehidupan bermasyarakat akan tetap damai dan terhindar dari konflik.

Nilai yang menonjol dalam hubungan manusia dengan masyarakat adalah nilai gotong royong, kerukununan, dan musyawarah atau mufakat.

\section{Nilai budaya dalam hubungan manusia dengan manusia lain}

Manusia sebagai mahluk sosial tentu memerlukan bantuan manusia lain di dalam kehidupannya. Rasa ingin dihargai, dihormati dan dianggap keberadaan nya mendorong manusia untuk bisa saling berkerjasama dan saling menjaga satu sama 
lain agar terhindar dari konflik horizontal sesama manusia.

Manusia dalam bermasyarakat pasti berhubungan dengan manusia lain ini membuktikan bahwa manusia merupakan mahluk sosial. Dalam kehidupan masyarakat seorang individu manusia tentu pasti mengalami masalah yang tentunya terkadang masalah tersebut hanya dapat dipecahkan antara satu individu manusia dengan dengan individu manusia lain.

Kondisi demikian merupakan hubungan manusia dengan manusia yang lainnya, tanpa kita sadari bahwa seorang manusia terkadang justru melakukan kesalahan tertentu dan ingin langsung meminta maaf secara individu kepada orang atau individu tanpa harus mengikutsertakan orang lain atau masyarakat yang lebih luas. Kondisi ini merupakan bentuk hubungan manusia dengan manusia yang lain.

Nilai yang menonjol dalam hubungan manusia dengan manusia lain adalah nilai kepatuhan, suka memaafkan, kesetiaan, keramahan, penyantun, kasih sayang, dan nilai keikhlasan.

5. Nilai budaya dalam hubungan manusia dengan diri sendiri

Setiap manusia tentu memiliki harapan dan cita-cita yang ingin di wujudkan dan dicapai, untuk menwujudkan cita cita atau harapan tentunya seorang manusia harus memiliki sifat semangat, disiplin, bekerja keras ataupun tekun.

Sifat seperti di atas merupakan nilai budaya dalam hubungan nanusia dengan diri sendiri, karena sifat diatas merupakan sifat yang dapat memberi dampak kepada individu sendiri.

Manusia harus mampu mangatur dirinya dan mengendalikan dirinya sendiri sebelum terjun ke dalam masyarakat, sifat mampu memahami, menghargai, sopan santun, merupakan tindakan dari sifat seseorang yang sudah mampu mengatur atau mengendalikan dirinya, dengan demikian maka kerukunan dan kedamaiaan akan didapatkan seorang idividu manusia ditenah masyarakat, karena alangkah baik jika manusia memiliki perananan bukan hanya untuk diri sendiri melainkan juga untuk orang lain.

Dari penjelasan di atas maka dapat di simpulkan bahwa nilai budaya yang menonjol dalam hubungan manusia dengan dirinya sendiri antara lain berusaha disiplin, menuntut ilmu, berusaha keras, tekun, kemauan yang keras, kerendahan hati, menjaga harga diri, menghargai adat dan agama, dan kekayaan. Teori yang dikemukakan oleh Djamaris (1996:3) tentang nilai-nilai budya yang dibagi atas beberapa sub bagian, yaitu: 1. Nilai budaya dalam hubungan manusia dengan Tuhan, 2. Nilai budaya dalam hubungan manusia dengan alam, 3. Nilai budaya dalam hubungan manusia dengan masyarakat, 4. Nilai budaya dalam hubungan manusia dengan manusia lain, 5. Nilai budaya dalam hubungan manusia dengan diri sendiri. Teori yang dikemukaan oleh Djamaris (1996:3) tentang nilai-nilai budya ini dijadikan sebagai pisau analisis yang akan digunakan dalam penelitian ini untuk menganalisis nilai budaya yang terdapat dalam Legenda Siti Payung.

\section{B. METODE PENELITIAN}

Penelitian ini merupakan penelitian yang menganalisis data dokumen berupa buku Antologi Cerita Rakyat Batu Bara yang diterbitkan oleh Balai Bahasa Provinsi Sumatera Utara Badan Pengembangan dan Pembinaan Bahasa Kementerian Pendidikan dan Kebudayaan pada tahun 2015.

Penelitian ini menggunakan metode penelitian kualitatif dengan menggunakan metode analisis analisis deskriftif, Menurut Sutedi (2009:58), metode analisis deskriptif adalah menggambarkan, menjabarkan suatu fenomena yang terjadi saat ini dengan menggunakan prosedur ilmiah untuk menjawab masalah secara actual. Penelitian ini akan mendeskripsikan atau menggambarkan apa yang menjadi masalah dalam dokumen atau buku, adapun dokumen 
atau buku yang dimaksud adalah teks cerita Legenda Siti Payung dalam buku Antologi Cerita Rakyat Batu Bara.

Data dan sumber data dalam penelitian ini adalah teks atau tuturan kata-kata atau kalimat yang ada dalam cerita Legenda Siti Payung dalam buku Antologi Cerita Rakyat Batu Bara.

Pengumpulan data dalam penelitian ini menggunakan teknik pustaka dan catat. Subroto (2007:47) menjelaskan teknik pustaka adalah teknik yang mempergunakan sumber-sumber tertulis untuk memeroleh data. Teknik analisis data yang digunakan dalam penelitian ini adalah secara kualitatif untuk mengetahui nilai budaya yang terdapat dalam Legenda Siti Payung.

\section{HASIL DAN PEMBAHASAN}

Legenda Siti Payung merupakan salahsatu legenda yang berasal dari Kabupaten Batu Bara, yang memiliki nilai-nilai Budaya, namun untuk mengetahui lebih jelas nilai budaya apa saja yang terkandung dalam legenda ini maka di bawah ini akan dipaparkan analisis tentang nilai-nilai kebudayaan dalam legenda siti payung.

\section{Nilai budaya dalam hubungan manusia dengan Tuhan}

Dalam Cerita Legenda Siti Payung (LSP) Nilai budaya dalam hubungan manusia dengan Tuhan tergambar dalam teks cerita LSP dimana Kamaruddin mengucap salam kepada Neneknya saat sampai dirumah neneknya, ucapan salam yang berlafas "Assalamualaikum" ini menunjukkan bahwa Khamaruddin memiliki hubungan dengan Tuhannya. Ucapan salam yang berlafas "Assalamualaikum" ini memiliki arti doa untuk keselamatan seseorang serta agar orang tersebut dirahmati oleh Tuhan. Nilai budaya dalam hubungan manusia dengan Tuhan dapat dilihat pada kutipan di bawah ini.
Di ujung kampung sebelum sampai ke ibu kota kerajaan ada sebuah rumah. Rumah itu dihuni oleh seorang nenek. Namanya Nenek Gabia. Kamaruddin singgah di rumah Nenek Gabia.

“Assalamualaikum, Nek," kata Kamaruddin.

“Waalaikum Salam," jawab nenek dari dalam rumah. Pintu Dibuka nenek. Dilihatnya ada seorang anak muda beruur antara 16 sampai 17 tahun. (Halaman: 150)

Dalam kutipan diatas tampak bahwa Kamaruddin menggunakan salam agama Islam untuk menyapa Neneknya saat sampai di rumah neneknya, kemudian neneknya juga membalas salam yang di sampaikan oleh Kamaruddin dengan jawaban "Waalaikumsalam" yang memiliki arti doa untuk keselamatan seseorang serta agar orang tersebut dirahmati oleh Tuhan.

Dapat diambil kesimpulan bahwa Kamarudiin dan nenek Gabia menunjukkan nilai budya dalam hubungan manusia dengan Tuhannya.

\section{Nilai budaya dalam hubungan manusia dengan alam}

Dalam cerita LSP Nilai budaya dalam hubungan manusia dengan alam juga ditemukan yang mana alam memberikan kebutuhan yang dibutuhkan manusia dan sebagai gantinya manusia tidak melakukan eksploitasi alam sehingga hubungan manusia dan alam tetap terjaga. Nilai budaya dalam hubungan manusia dengan alam dapat dilihat pada kutipan di bawah ini.

Pada waktu itu Kamaruddin masih kecil dan pekerjaannya membantu ayahnya mencari kayu di hutan. Lama-kelamaan Kamaruddin tumbuh menjadi remaja yang bertubuh tegap dan kuat karena selalu bekerja keras mengangkat kayu dari hutan. (Halaman: 104)

Dalam kutipan diatas tampak bahwa Kamaruddin dan Ayahnya memiliki 
pekerjaan mencari kayu di hutan, ini menunjukkan bahwa Kamaruddin dan ayahnya tidak melakukan penebangan hutan, mereka hanya berusaha mencari kayu yang sudah disediakan oleh alam saja, sebenarnya hasil hayu yang mereka ambil dari hutan tidaklah begitu bayak menghasilkan uang karena mereka hanya mengambil secukupnya saja untuk dijual ke kota, namun jika Kamaruddin dan ayahnya mengambil Kayu secara berlebihan dari hutan tentu mereka sudah menjadi kaya raya. Sikap Khamaruddin dan ayahnya yang mengambil kayu secukupnya untuk keperluan membeli makanan merupakan sikap menjaga lingkungan yang memiliki nilai budaya dalam hubungan manusia dengan alam.

\section{Nilai budaya dalam hubungan manusia dengan masyarakat}

Dalam cerita LSP Nilai budaya dalam hubungan manusia dengan masyarakat tergambar dengan jelas bahwa dalam cerita LSP ada 7 putra kerajaan yang memiliki niat untuk meminang atau melamar putri raja yang bernama Siti Payung, namun ternyata Raja memilih untuk menikahkan Siti Payung dengan Kamaruddin. Keputusan raja menikahkan putrinya dengan Kamaruddin menimbulkan kegaduhan dan dendam dari 7 putra kerajaan yang telah ditolak oleh Siti Payung.

Nilai budaya dalam hubungan manusia dengan masyarakat dapat tergambardalam kutipan teks cerita LSP dibawah ini.

Datanglah surat dari kerajaan Berhan kepada raja dan

Kamaruddin. Surat yang jatuh pada raja isinya "Kalau sayang anak, berikan nyawa!" surat yang jatuh kepada Kamaruddin isinya, "Kalau sayang istri, berikan nyawa."

Raja Tua, ayah Siti Payung takut luar biasa, karenakerajaan yang mengancam itu adalah kerajaan besar. Akan tetapi Kamaruddin tidak takut. Dia membalas surat yang dikirim kepadanya. Balasannya singkat, "Sayang istri!". Sayang istri berarti perang. (Halaman: 109)

Pada kutipan di atas tampak bahwa kamaruddin dan Raja mendapat surat ancaman dari ke 7 putra kerajaan yang sudah ditolak pinangannya oleh Siti Payung. Pada dasarnya di awal kutipan di atas merupakan nilai budaya yang tidak baik karena menunjukkan sikap mengancam sedangkan pada kutipan selanjutnya menunjukkan sikap yang patriot yang ditunjukkan oleh Kamaruddin dengan membalas surat dengan jawaban "Sayang Istri" Sayang istri berarti perang.

Sikap yang tunjukkan oleh Kamaruddin adalah sikap patriot pejuang yang menunjukkan sukap melindungi keluarganya dari ancaman 7 diluar sana.

Nilai budaya dalam hubungan manusia dengan masyarakat tergambar pada sikap patriot Kamaruddin yang berusaha membela yang benar dan menolak kejahatan yang dilakukan oleh 7 kerajaan diluar kerajaan yang di pimpin oleh Ayahanda Siti Payung.

\section{Nilai budaya dalam hubungan manusia dengan manusia lain}

Dalam cerita LSP nilai budaya dalam hubungan manusia dengan manusia lain tergambar jelas dengan adanya sikap saling membantu, seperti sikap yang dilakukan oleh Kamaruddin terhdap ayahnya yaitu membantu ayahnya mencari kayu dihutan, begitu juga dengan sikap membantu kamaruddin terhadap neneknya yaitu membantu neneknya membuat bunga sehingga bunga yang dijual neneknya menjadi laris saat dijual. Selain itu juga sikap ramah tamah menanyakan kabar merupakan sikap yanag bernilai budaya dalam hubungan manusia dengan manusia, sikap ini ditunjukkan oleh Nenek Gabia yang menanyakan kabar Kamaruddin saat Kamaruddin dating kerumah Nenek Gabia.

Nilai budaya dalam hubungan manusia dengan manusia lain dapat dilihat pada kutipan di bawah ini. 
"Naiklah, Cucu," kata nenek Gabia.

"Patutlah nenek tak enak makan, tak enak tidur, rupanya cucu nenek yang datang," kata nenek Gabia. Naiklah Kamaruddin tadi ke rumah nenek Gabia.

"Apa kabar, Cucu?" tanya nenek. (Halaman: 105)

Pada kutipan diatas tampak bahwa nenek Gabia memberikan penyambutan yang hangat kepada cucunya Kamaruddin, sealin itu nenek Gabia juga menanyakan kabar Kamaruddin, sikap ini merupakan sikap yang menenangkan hati lawan bicaranya sehingga merasa dihargai.

Nilai budaya dalam hubungan manusia dengan manusia lain dapat dilihat pada kutipan di bawah ini.

"Nek, aku mau membeli bunga Nenek."

"Sepertinya bunga-bunga ini bukan bikinan orang tua," kata Tuan putri Siti Payung dalam hati.

"Nenek di rumah tinggal bersama siapa?" Kato Tuan putri.

"Tidak dengan siapa-siapa, nenek sendirian di rumah, Tuan Puteri, , jawab nenek.

"Biarlah kubeli bunga Nenek, ini," kata tuan putri (Halaman: 106)

Pada kutipan diatas tampak bahwa nenek Gabia sedang berkomunikasi dengan Siti Payung membahas tentang bunga yang dijual oleh Nenek Gabia, pada kutipan diatas tampak bahwa nenek Gabia dan Siti Payung berkomunikasi sopan tanpa menggunakan bahasa yang kasar. In I menunjukan nilai budaya hubungan manusia dengan Manusia yaitu nilai komunikasi yang baik saat bertansaksi berjualan bunga.

5. Nilai budaya dalam hubungan manusia dengan diri sendiri

Dalam Cerita LSP Nilai budaya dalam hubungan manusia dengan diri sendiri tergambar dari sikap Kamaruddin yang bekerja keras membantu ayahnya untuk mencari kayu di hutan. Nilai budaya dalam hubungan manusia dengan manusia lain dapat dilihat pada kutipan di bawah ini.
Lama-kelamaan
Kamaruddin
tumbuh menjadi remaja yang
bertubuh tegap dan kuat karena selalu bekerja keras mengangkat kayu dari hutan. (Halaman: 104)

Pada kutipan diatas tampak bahwa Kamaruddin memiliki sikap pekerja keras dan tekun dalam membantu ayahnya mengambil kayu di hutan, ini merupakan nilai budaya dalam hubungan manusia dengan diri sendiri.

Selain itu nilai budaya dalam hubungan manusia dengan diri tergambar dari karakter tokoh Siti Payung yang mana untuk menghilangkan rasa penasarannya terhadap bunga yang di jual nenek Gabia maka Siti Payung berusaha memberi tandangan kepada nenek Gabia membuat Bunga di hadapannya, karena nenek Gabia tidak bisa membuktikannya maka Siti Payung meminta izin Ayahnya untuk pergi berkunjung ke rumah Nenek Gabia. Sikap rasa penasaran yang tinggi yang ada pada Siti Payung serta usahanya untuk mendapatkan jawaban atas rasa penasarannya itu merupakan sikap kegigihan diri.

Nilai budaya dalam hubungan manusia dengan diri sendiri dapat dilihat pada kutipan di bawah ini.

Berkatalah tuan putri, "Betul kan, Nek? ada orang di rumah Nenek. Kalau begitu aku ikut ke rumah Nenek. Aku mau melihat siapa yang di rumah Nenek!" kata tuan putri.(Halaman 108)

Pada kutipan diatas tampak bahwa Siti Payung penasaran dengan bunga yang di jual oleh Nenek Gabia, kemudian Siti Payung meminta agar nenek mengikutkan Siti Payung kerumah nenek, permintaan Siti Payung tentu tidak berani di tolak oleh Nenek Gabia, karena Siti Payung adalah Putri Raja. Namun sikap gigih Siti Payung untuk menjawab rasa penasarannya 
merupakan sikap yang bernilai budaya dalam hubungan manusia dengan diri sendiri.

\section{SIMPULAN}

Dari hasil analisis dapat disimpukan bahwa LSP memiliki 5 nilai budaya yaitu 1 . Nilai budaya dalam hubungan manusia dengan Tuhan sikap berdoa 2. Nilai budaya dalam hubungan manusia dengan alam yaitu sikap menjaga lingkungan. 3. Nilai budaya dalam hubungan manusia dengan masyarakat yaitu sikap patriotis membela yang benar. 4.Nilai budaya dalam hubungan manusia dengan manusia lain yaitu sikap sopan dalam berkomunikasi menenangkan hati lawan bicaranya. , 5. Nilai budaya dalam hubungan manusia dengan diri sendiri yaitu kegigihan diri. Tentu jika digali lebih mendalam pada cerita LPS maka akan kita temukan nilai-nilai yang lain lagi.

Pada dasarnya hasil analisis tentang nilai budaya yang terkandung dalam cerita LSP ini dapat dimanfaatkan sebagai edukasi kepada generasi muda untu bersikap dengan menonjolkan nilai-nilai yang terkandung dalam cerita LSP.

\section{DAFTAR PUSTAKA}

Balai Bahasa Provinsi Sumatera Utara. 2015 Antologi Cerita Rakyat Batu Bara. Terjemahan dalam Tiga Bahasa, Batu Bara- Indonesia- Inggris. Balai Bahasa Provinsi Sumatera Utara Badan Pengembangan dan Pembinaan Bahasa Kementerian Pendidikan dan Kebudayaan. Medan.

Danandjaja, James. 1984. Folklor Indonesia ilmu gosip dongeng dan lain-lain. PT. Grafiti Press. Jakarta.

Djamaris, Edwar. 1990. Menggali Khazanah Sastra Melayu Klasik (Sastra Indonesia Lama). Jakarta: Balai Pustaka.

Febrianti. Binar Kurniasari, 2018. Nilainilai budaya dalam cerita rakyat kalimantan barat burung arue dan burung talokot. SIROK BASTRA, Vol. 6 No. 2, Desember 2018: 171184.

Hasanuddin WS. 2003. Transformasi dan Produksi Sosial Teks Melalui Tanggapan dan Penciptaan Karya Sastra. Bandung: Dian Aksara Press. Merdiyatna.Yang Yang, 2019. Nilai-Nilai Budaya Dalam Cerita Rakyat Panjalu. Jurnal Pendidikan Bahasa dan Sastra Indonesia ISSN: 25500848; ISSN Online : 2614-2988 Vol. 4, No. 1, September 2019

Subroto D, Edi. 2007. Pengantar Metode Linguistik Struktural. Surakarta: LPP UNS dan UNS Press.

Sutedi. Adrian, 2009, Metode Penelitian Hukum, Sinar Grafika, Jakarta.

Sibarani Robert (2014) Antropolinguistik. Medan, Penerbit Poda.Setiawan, Yulianto Budi. Dkk. (2013). Bias Gender Dalam Cerita Rakyat (Analisis Naratif Pada folklore dengan Cerita Rakyat Indonesia Bawang Merah Bawang Putih. Jurnal Komunikasi. Vol.5 No.2. Semarang: Universitas Semarang. 